\title{
SIMULADORES E APOIO CONTÁBIL NA AVALIAÇÃO DOS TRADE-OFFS DE CUSTOS LOGÍSTICOS
}

\section{SIMULATION TOOLS AND ACCOUNTING SUPPORT FOR ASSESSING LOGISTICS COST TRADE-OFFS}

\section{SIMULADORES Y APOYO DE LA CONTABILIDAD EN LA EVALUACIÓN DE LOS TRADE-OFFS DE COSTOS LOGÍSTICOS}

Recebido em: 22-12-2019

Avaliado em: 01-10-2020

Reformulado em: 12-11-2020

Aceito para publicação em: 10-02-2021

Publicado em: 21-04-2021

Editor Responsável: Franciele Beck
Juliana Ventura Amaral ${ }^{1}$

Reinaldo Guerreiro ${ }^{2}$

\section{RESUMO}

As interações entre as atividades logísticas impactam os custos e demandam uma visão global dos processos logísticos. A avaliação dos trade-offs é a chave para que as inter-relações intangíveis de custos entre as atividades convertam-se em melhorias tangíveis no lucro. Nesse sentido, este estudo teve o objetivo averiguar quais fatores explicam a extensão de avaliação dos trade-offs de custos logísticos. Para tanto, houve a coleta de dados por meio de um questionário enviado a 243 profissionais logísticos das maiores empresas comerciais e industriais do Brasil. Análises de regressão linear múltipla foram conduzidas para identificar a relação entre a avaliação dos trade-offs (variável dependente) e a utilização de simuladores de custo e o apoio contábil (variáveis independentes). As 73 respostas recebidas permitiram identificar relações positivas e estatisticamente significativas entre as variáveis. Os achados revelaram que a avaliação dos trade-offs de custos logísticos é explicada pela utilização de simuladores de custo e pelo apoio contábil na formulação das soluções logísticas. Pode-se, assim, concluir que informações ofertadas pela área contábil e tratadas pelos simuladores viabilizam a avaliação dos trade-offs e, deste modo, favorecem a tomada da decisão logística. Futuras pesquisas podem estudar detalhes dessas relações, avaliando, por exemplo, as características dos simuladores e da controladoria que mais favorecem a avaliação dos trade-offs.

Palavras-chave: Trade-offs. Custos. Logística. Simuladores. Contabilidade.

\footnotetext{
${ }^{1}$ Doutora em Ciências (Controladoria e Contabilidade) pela FEA/USP; E-mail: juliana.ventura.amaral@usp.br

${ }^{2}$ Doutor e Livre-Docente em Controladoria e Contabilidade pela FEA/USP; Professor Titular do Departamento de Contabilidade e Atuária da FEA/USP; E-mail: reiguerr@usp.br
} 


\begin{abstract}
The interactions among logistical activities have significant impacts on the costs and, as a consequence, an overview of logistics processes is needed. Assessing logistics cost trade-offs is key to convert intangible cost interrelationships into tangible improvements in income. In this sense, this study's major objective was to investigate factors explaining the assessment of logistics cost tradeoffs. Data was collected through a questionnaire sent to 243 logistics professionals of the Brazil's largest commercial and industrial companies. Multiple linear regression models were used to identify the relationship between the assessments of trade-offs (dependent variable) and the use of simulation tools and the accounting support (independent variables). Seventy-three companies served as sample in this study, and their responses revealed positive and statistically significant relationships between variables. Based on the results, it could be stated that the assessment of logistics cost trade-offs is explained by the use of simulation tools and by the accounting support. It can be concluded that information offered by management accounting and supported by simulation tools enables the assessment of trade-offs and thus favors logistical decision-making. Future research may study these relationships' details, as the characteristics of the simulation tools and management accounting that most favor the assessment of trade-offs.
\end{abstract}

Keywords: Trade-offs. Costs. Logistics. Simulation tools. Accounting.

\title{
RESUMEN
}

Las interacciones entre las actividades logísticas impactan los costos e requieren una visión general de los procesos logísticos. La evaluación de los trade-offs de costos logísticos es clave para que las interrelaciones de costos intangibles se conviertan en mejoras tangibles en las ganancias. En este sentido, este estudio tuvo como objetivo determinar qué factores explican el alcance de la evaluación de los trade-offs de costos logísticos. Los datos fueran reunidos través de un cuestionario enviado a 243 profesionales de logística de las empresas comerciales e industriales más grandes de Brasil. Se realizaron análisis de regresión lineal múltiple para identificar la relación entre la evaluación de los trade-offs (variable dependiente) y el uso de simuladores de costos y el apoyo contable (variables independientes). Con las 73 respuestas recibidas, se puede identificar relaciones positivas y estadísticamente significativas entre las variables. Los hallazgos revelaron que la evaluación de los trade-offs es explicada por el uso de simuladores de costos y por el apoyo de la contabilidad. Por tanto, se puede concluir que la información ofrecida por el área de contabilidad y manejada por los simuladores permite evaluar los trade-offs y favorece así la toma de decisiones logísticas. La investigación futura puede estudiar los detalles de estas relaciones, evaluando, por ejemplo, las características de los simuladores y de contabilidad que más favorecen la evaluación de los tradeoffs.

Palabras-clave: Trade-offs. Costos. Logística. Simuladores. Contabilidad.

\section{INTRODUÇÃO}

Napolitano (2011) argumenta que os executivos do alto escalão normalmente desejam entender como a logística se relaciona com a dimensão econômico-financeira da empresa e com o serviço ao cliente. Contudo, eles e os demais profissionais costumam ver os custos logísticos como um expressivo dispêndio (Lin, Collins, \& Su, 2001), em vez de perceberem que os mesmos podem ser uma potencial fonte de economia (Moons, Waeyenbergh, \& Pintelon, 2019). Rantasila e Ojala (2015) destacam ainda que, no contexto global, um melhor entendimento dos custos logísticos é importante não apenas para avaliar e traçar estratégias, mas para melhorar a competitividade da indústria como um todo. 
Essa percepção da logística como um mero dispêndio, e não como uma fonte de economia, há muito tempo tem sido lamentada na literatura. Little (1977), por exemplo, já na década de 1970, defendia que nenhuma área da empresa oferece tantas oportunidades quanto a logística, uma vez que: (i) a gestão das atividades logísticas envolve diversas áreas; (ii) o escopo das operações logísticas é extenso, pois vai das matérias-primas até o consumidor final; (iii) a variedade de custos indiretos e ocultos na logística é ampla; (iv) há interações com outras organizações na pré e pós-produção; e (v) o ciclo completo das operações logísticas é longo, porque vai da compra de matérias-primas à distribuição de produtos acabados.

Lewis e Culliton (1956) revelaram que as decisões logísticas, para proporcionarem oportunidades de economia, não devem ser consideradas isoladamente, devido aos interrelacionamentos de custos das atividades, isto é, devido à existência de trade-offs de custos logísticos. O transporte aéreo, por exemplo, pode substituir o transporte aquático se o incremento no custo do transporte for compensado por menores custos de estoques, de armazenagem e de embalagem, devido à maior velocidade e à maior confiabilidade dos aviões (Amaral \& Guerreiro, 2014).

Os trade-offs de custos logísticos referem-se às trocas compensatórias entre o aumento em algum custo logístico e a diminuição em outro custo logístico, e/ou o aumento no nível de serviço oferecido ao cliente (Faria \& Costa, 2007). Sua importância foi expandida com a sustentação de que todas as soluções logísticas devem objetivar a otimização do custo total, não a redução dos custos individuais. Afinal, não há custo logístico que possa ser modificado sem afetar os outros custos e/ou o serviço ao cliente. A análise das possíveis reações para cada ação proposta é necessária para que seja identificada qual solução proporciona o custo total mínimo e o nível de serviço ótimo (Amaral \& Guerreiro, 2014).

A avaliação de atividades e de suas inter-relações é crucial para entender como a logística pode impactar a lucratividade da empresa, visto que uma mesma tarefa poder ser executada de distintas maneiras e induzir a diferentes custos e desempenhos (Busher \& Tyndall, 1987). Com a avaliação dos trade-offs, as inter-relações intangíveis de custos entre as atividades logísticas podem ser convertidas em melhorias tangíveis no lucro (Lekashman \& Stolle, 1965).

A disponibilidade de informações dos custos associados a cada componente logístico é, portanto, imperativa para avaliar os trade-offs (Lambert \& Armitage, 1979; Lambert \& Quinn, 1981). Isso ocorre porque o cálculo dos trade-offs e a análise do custo total dependem de segregação e evidenciação detalhada dos custos logísticos. O problema é que esses custos estão, por vezes, dispersos em várias contas contábeis, como overhead, despesas de vendas e despesas gerais. Ainda, abandonam o respeito ao princípio da competência, ao confrontar custos de um período com receitas de outro período (Lambert \& Armitage, 1979). O controle dos custos logísticos necessita de informações contábeis precisas, pois a redução em custos de uma atividade invariavelmente causa aumentos em custos de outra(s) (Tyndall \& Busher, 1985).

A disponibilidade de simuladores de custos (Lekashman \& Stolle, 1965) e de uma contabilidade voltada ao apoio à logística (Hälinen, 2015) podem facilitar esse controle. Logo, este artigo tem o objetivo de examinar os fatores que explicam a extensão que os profissionais logísticos avaliam os trade-offs de custos logísticos, especificamente avaliando se a utilização de simuladores de custo e o apoio contábil na formulação das soluções logísticas impactam a extensão de avaliação dos trade-offs. Para tanto, este estudo é norteado pela seguinte questão de pesquisa: Quais fatores explicam a extensão de avaliação dos trade-offs de custos logísticos?

Essa investigação justifica-se pelos elevados custos ainda apresentados pela logística. O ILOS - Especialistas em Logística e Supply Chain (2017), por exemplo, apurou que, em 2016, os custos logísticos consumiram 12,3\% do PIB do Brasil. Ademais, de acordo com estudo do Banco Mundial (Arvis, Ojala, Wiederer, Shepherd, Raj, Dairabayeva, \& Kiiski, 2018), a satisfação com a infraestrutura logística é especialmente baixa na região da América Latina. O Brasil, especificamente, apresenta um índice de desempenho logístico, medido pela facilidade ou dificuldade de transportar mercadorias em geral, que corresponde a apenas $72,1 \%$ do melhor desempenho, apresentado pela 
Alemanha. Assim, este estudo pode contribuir com a prática ao identificar formas de otimizar os custos e, dessa forma, melhorar o desempenho.

Cabe ressaltar também que a literatura mundial sobre trade-offs é ainda incipiente e parcial. Waller e Fawcett (2012) expuseram a falta de estudos que explorem, sob vários prismas, o conceito do custo total. Não obstante, os poucos trabalhos que discursam sobre trade-offs concentram-se em um número restrito de atividades. Essa constatação corrobora a defesa de Mentzer, Min e Bobbitt (2004), de que os pesquisadores logísticos têm desenvolvido estudos limitados a componentes individuais logísticos e feito pouco esforço para construir uma teoria unificada da logística. Logo, abordar esses pontos propicia condições de contribuir com a literatura do tema.

\section{REFERENCIAL TEÓRICO}

\subsection{Trade-offs de custos logísticos}

Os trade-offs de custos podem ser encontrados em quaisquer conjuntos de atividades logísticas. A literatura, contudo, enfatiza a exposição dos trade-offs envolvendo o transporte, uma vez que essa é a atividade logística que mais interage com as demais atividades, por ser a principal responsável pela criação das utilidades de tempo e lugar. A utilidade lugar é criada na medida em que ocorre a movimentação entre dois pontos, já a utilidade tempo é criada a partir da rapidez e da constância do movimento entre esses dois pontos (Coyle, Langley Jr., Gibson, Novack, \& Bardi, 2008).

Transportes tempestivos possibilitam que os estoques permaneçam por pouco tempo em trânsito e oferecem condições de certeza que permitem reduzir o nível dos estoques de segurança. Induzem, desse modo, à compensação entre elevados custos de transportes e baixos custos de estoques (Bhatnagar, \& Teo, 2009). Transportes morosos exibem a situação inversa e, embora exibam custos de menor monta, acarretam a estocagem por longo tempo (em trânsito) e demandam maior quantidade de estoques de segurança, devido à ausência de certeza durante o tempo que as mercadorias estão em trânsito (Bhatnagar \& Teo, 2009).

Cabe, portanto, avaliar o que mais compensa: economizar nos custos de estoques ou nos custos de transporte. Chow (2008) ilustrou uma situação na qual o custo total poderia ser minimizado pelo aumento nos custos relacionados ao estoque, concomitante a uma diminuição nos custos de transporte. Segundo o autor, as importações do leste asiático costumavam chegar pelos portos da costa oeste e dirigir-se rapidamente ao leste dos Estados Unidos e do Canadá pelo transporte ferroviário e rodoviário. O aumento no preço dos combustíveis elevou o custo dos transportes terrestres e fez com que as importações começassem a entrar diretamente pela costa leste americana, via trânsito marítimo no Panamá e no canal de Suez. Essa manobra ampliou a permanência e o custo dos estoques, mas possibilitou a redução do custo de transporte.

O tipo de produção (puxada versus empurrada) também implica em trade-offs de custos entre o transporte e os estoques. A produção puxada, por implicar na fabricação de apenas o que foi demandado, tende a manter poucos estoques, sobretudo de matérias-primas. A produção empurrada, por sua vez, fabrica os produtos antes da solicitação dos clientes e tende a manter larga quantidade de estoques. Dessa forma, a produção puxada propende a exibir custos de estoques inferiores aos custos da produção empurrada, mas, em compensação, implica em aquisições de pequena quantidade de matérias-primas, que tornam inviável a obtenção de economias de escala no transporte (Jammernegg \& Reiner, 2007).

A seleção da estratégia de armazenagem também envolve trade-offs com o transporte. A localização impacta diretamente os custos. Solakivi, Hofmann, Töyli e Ojala (2018) exemplificam esse aspecto ao compararem o custo de transporte da Suíça ao custo de transporte da Finlândia. Eles concluíram que apesar de em ambos os locais o transporte ser comumente terceirizado, na Finlândia ele tende a ser maior, porque o país está distante do epicentro europeu, enquanto a Suíça está localizada em uma região central da Europa. 
A centralização em poucos armazéns ganhou força nas organizações entre os anos 1970 e 1990 e foi propulsionada pelos aumentos de velocidade e de confiabilidade das operações de transporte (Mckinnon, 2007). Ao se centralizar as instalações, diminui-se o custo de armazenagem, pois a mão de obra, as instalações e os equipamentos devotados à atividade são reduzidos. Contudo, a ausência de proximidade com os vários mercados de consumo e de fornecimento exige mais movimentações e aumenta o custo de transporte. Souza, Weber e Campos (2015) frisam que o uso de centro de distribuição ajuda na redução dos custos de transportes, sobretudo no Brasil, pela legislação que regula a atuação dos condutores em viagens longas.

$\mathrm{Na}$ descentralização, a situação é inversa e o custo de transporte é minorado, enquanto o custo de armazenagem é majorado. Ressalta-se, todavia, que na descentralização, o custo de transporte é reduzido até certa quantidade de armazéns. Com uma quantidade muito grande, os veículos não mais conseguem ocupar sua capacidade máxima e começam a transportar menor quantidade de cargas, o que inviabiliza a obtenção de economias de escala (Lambert \& Stock, 1992).

Napolitano (2011) relata que as empresas dos Estados Unidos visavam, até a década passada, centralizar suas fábricas para reduzir custos de armazenagem e de estoques. Mas, devido às crescentes taxas de fretes, elas têm, na atualidade, preferido aderir pela descentralização e mais instalações. Talley e $\mathrm{Ng}$ (2017) frisam que enquanto estão na rede de transporte, as cargas incorrem nos custos de estoque, sobretudo pela depreciação e pelos seguros.

A decisão de manter ou não nos veículos produtos que serão novamente transportados em um curto espaço de tempo também implica trade-offs entre o transporte e a armazenagem. Ao optar pela manutenção dos produtos nos veículos, reduzem-se os manuseios de descarga e recarga e, consequentemente, o custo de manuseio nos armazéns, mas tem-se um maior custo de transporte por diárias adicionais de frete. Da mesma forma, a opção por percorrer um itinerário mais longo até o ponto de destino novamente implica em trade-offs entre as atividades e é uma alternativa para armazéns que possuem capacidade limitada (Bowersox \& Closs, 2009).

Além do percurso selecionado, a escolha da embalagem usada no transporte envolve conflitos de custos. A embalagem pode padronizar as dimensões das mercadorias, o que facilita o acondicionamento, possibilita a otimização cúbica dos veículos e permite reduzir o número de viagens na movimentação total da carga (Vernuccio, Cozzolino, \& Michelini, 2010). A uniformização, viabilizada com as embalagens, facilita ainda o manuseio e elimina a necessidade de equipamentos especializados para o manejo (Lambert \& Stock, 1992). No que tange à identificação dos produtos, o aumento de informação proporcionado pelas embalagens facilita o tratamento dado às mercadorias e diminui atrasos de embarque e possíveis extravios.

Além disso, a proteção das embalagens permite que a seleção do transporte se estenda a possibilidades menos dispendiosas (Lambert \& Stock, 1992). A movimentação de produtos que podem se danificar se forem expostos à água, por exemplo, apresenta duas soluções: (i) uso de veículos descobertos, como certos tipos populares de caminhões, vagões e navios, combinado ao uso de embalagens a prova d'água; ou (ii) uso de veículos cobertos articulado ao uso de embalagens não a prova d'água. Os transportes descobertos normalmente apresentam fretes mais atrativos que os transportes cobertos, mas carecem de embalagens a prova d'água, cujo custo é superior às embalagens não a prova d'água. Parker (1962) corrobora esse entendimento e defende que a seleção do modal de transporte afeta os custos das embalagens.

Outro aspecto que merece ser trazido na discussão dos trade-offs de custos entre as embalagens e o transporte versa sobre a utilização de embalagens retornáveis. Este tipo de embalagem possibilita reduzir a quantidade total de embalagens adquiridas, mas, para viabilizar o reuso, requer transportes adicionais no recolhimento (Stop Waste Partenership \& Reusable Pallet \& Container Coalition, 2008). Wu e Closs (2009) vão além e revelam que o uso não só de embalagens retornáveis, mas de materiais e de peças do fluxo reverso reduz a quantidade de aquisições e possibilita reduzir o custo dos estoques, mas demanda movimentações para conduzir os materiais dos pontos de recolhimento aos pontos de reuso, ampliando os custos de transporte. 
Passando agora à relação entre o transporte e o serviço ao cliente, cabe destacar o impacto que o transporte traz na responsividade, isto é, no tempo que a empresa leva para atender aos pedidos. Entregas em pequenos lotes, requeridas para que as solicitações sejam rapidamente enviadas aos consumidores não proporcionam economias de escala e induzem a altos custos de transporte (Chopra \& Meindl, 2003). A agregação temporária em maiores lotes, por sua vez, combina pedidos ao longo do tempo e retarda as entregas, o que reduz a responsividade e diminui o nível de serviço, mas possibilita contrair economias de escala e diminuir o custo de transporte (Chopra \& Meindl, 2003). Vanelslander, Deketele e Van Hove (2013) explicam que a quantidade de clientes por rota, isto é, a densidade de clientes e a distância entre a empresa e o cliente podem ser os principais determinantes dessa decisão.

Na mesma linha, meios de transportes que possuem longos tempos de espera (i.e., marítimo) apresentam um custo menor do que meios de transportes rápidos (i.e., aéreo), mas oferecem baixa responsividade ao cliente e, consequentemente, baixo nível de serviço (Lee \& Billington, 1992). Arvis, Raballand e Marteau (2007) acrescentam que transportadores individuais e informais exibem ínfimas taxas de frete, mas são menos confiáveis e podem prejudicar o nível de serviço oferecido ao cliente. Por outro lado, companhias formais e modernas cobram elevadas taxas de fretes, mas prestam serviços fidedignos de baixa incerteza que viabilizam uma boa responsividade ao cliente. Na Amazon UK, por exemplo, optou-se por não oferecer itens congelados ou perecíveis em decorrência das complexidades e dos custos do transporte desses tipos de mercadorias (Vanelslander et al., 2013).

O serviço ao cliente também é impactado pelas escolhas inerentes à atividade de armazenagem. Moghaddam, Javadi e Molana (2019) defendem que vários esforços têm sido feitos no sentido de modelar e otimizar o desenho da rede logística, visando reduzir os custos e aumentar o nível de serviço, mas lamentam que ainda há poucos trabalhos que abordem esse tópico de modo extensivo, isto é, considerem simultaneamente aspectos estratégicos e táticos.

À medida que se amplia a quantidade de armazéns, há aumento da responsividade ao cliente, mas há também aumento nos estoques e no custo de armazenagem pela ampliação de mão de obra, de instalações e de equipamentos dedicados aos manuseios internos e à manutenção dos armazéns. A centralização de estoques em poucos armazéns, em oposição, diminui o custo de armazenagem, mas reduz o nível de serviço ao cliente, pois a menor disponibilidade de produtos tende a diminuir a responsividade (Gopal \& Cypress, 1993).

Os graus de tecnologia e de automatização dos armazéns são outros fatores que originam trade-offs entre o serviço ao cliente e à armazenagem (Miller \& Smith, 2011). Russell e Meller (2003) desenvolveram um modelo que auxilia na decisão entre automatizar ou não automatizar os processos de armazenagem, afinal, sistemas automatizados, em comparação a sistemas manuais, requerem mais investimentos e conduzem a mais custos fixos de armazenagem, sobretudo de depreciação, manutenção, custo de capital e/ou aluguel dos equipamentos e dos sistemas de informação, mas oferecem eficiência que possibilita prestar serviços mais tempestivos e consistentes.

Lambert e Lewis (1983) enfatizaram esse entendimento e argumentam que a automação e a integração dos sistemas reduzem o tempo decorrido no ciclo do pedido e ampliam a sua consistência. Kämäräinen e Punakivi (2002) trazem o exemplo da Webvan, que apenas separa os pedidos a partir de centros de distribuição on-line, o que lhe demandou pesados investimentos em automação, mas propiciou velocidade e amplo desempenho nos processos de armazenagem.

Além do serviço ao cliente, os sistemas de armazenagem, deliberados no layout dos armazéns definem os níveis de estoques e, consequentemente, seus custos. A adoção de sistemas precários culmina em baixos custos de armazenagem, mas eleva os riscos dos estoques (Donselaar, Woensel, Broekmeulen, \& Fransoo, 2006).

Moghaddam, Javadi e Molana (2019) destacam o papel da logística em minimizar a perda de produtos perecíveis, uma vez que cerca de 20 a $60 \%$ de toda a produção do mundo é perdida após ter sido colhida. Em supermercados, por exemplo, a adoção de sistemas de controle de estocagem e de solicitação de compras inapropriados pode fazer que produtos perecíveis sejam perdidos por terem 
seu prazo de validade ultrapassado (Donselaar et al., 2006). Por outro lado, o uso da tecnologia RFID, que exige equipamentos e materiais relativamente dispendiosos, conduz a custos de armazenagem mais elevados que o código de barras, mas assegura a confiabilidade do nível de estoque e reduz os riscos dos inventários (Hozak \& Collier, 2008).

$\mathrm{Na}$ agricultura, esse trade-off também existe. De acordo com Auler, Teixeira, Teixeira e Baptista (2009), o processo de modernização das granjas no Brasil passa constantemente por melhorias. Os autores mencionam que mais de 15 milhões de aves alojam-se em instalações modernas, que exigem investimentos iniciais elevados, mas viabilizam uma alta densidade de alojamento, o que pode otimizar os níveis de estoque.

Outro trade-off entre a armazenagem e os estoques origina-se com a realocação, que se refere à transferência de estoque de um armazém a outro para evitar a sua obsolescência. A possibilidade de realocação minimiza a obsolescência dos estoques, pois o produto é transferido de um ponto em que não é procurado a outro ponto em que poderá ser demandado, mas traz custos adicionais de armazenagem, originados com movimentações extras, por exemplo, expedição da carga no atual armazém e recepção e manuseio interno no futuro armazém (Lambert \& Lalonde, 1976).

No que tange às estratégias operacionais, adverte-se que a separação dos pedidos nos armazéns compromete o nível de estoques. A separação por lotes, por exemplo, aguarda a consolidação de vários pedidos e ocorre simultaneamente em um único tratamento $(\mathrm{Gu}$, Goetschalckx, \& Mcginnis, 2010). Essa característica, apesar de reduzir o custo de armazenagem pelo menor número de pessoal e de equipamentos dedicados às separações e às movimentações individuais, amplia o custo de manutenção de estoques, pois exige que lotes com o número mínimo de pedidos sejam formados. Stank, Esper, Goldsby, Zinn e Autry (2019) destacam que processamentos de pedidos mais velozes podem reduzir os estoques, os custos de armazenagem e de transporte, além de melhorarem o nível de serviço.

A precisão na previsão de demanda, da mesma forma, impacta os custos com os estoques, pois reduz os erros e melhora a disponibilidade dos produtos (Jain, 2004; Jain, 2007). Erros na previsão podem ocasionar um super ou um sub dimensionamento nos estoques (Ishfaq \& Raja, 2020). O aumento na precisão é alcançado com modelos mais complexos, cujos custos no desenvolvimento, na manutenção e na operação são maiores. Contudo, ela evita uma estimativa superdimensionada, que ocasiona a manutenção de estoques que não serão demandados. Também inibe uma estimativa subdimensionada, que causa o desencadeamento de ações e processamentos não planejados, nas quais o preço cobrado pelos estoques pode ser mais elevado (Jain, 2004; Jain, 2007). Assim como o transporte, a armazenagem também é impactada pelo tipo de embalagem selecionada (Faria \& Costa, 2007). A utilização de embalagens protetoras a prova d'água, por exemplo, permite que os produtos sejam mantidos em locais externos, cujos custos tendem a ser baixos. Em contraposição, embalagens não a prova d'água, que são menos dispendiosas, apresentam como exigência o armazenamento em locais cobertos e onerosos.

O aumento de informações nas embalagens também melhora o rastreio e a comunicação interna referente aos produtos. A recepção, o manuseio interno e a expedição são facilitadas com a padronização e com a unitização das mercadorias (Vernuccio et al., 2010). A movimentação de materiais a granel, por exemplo, apresenta grau de dificuldade superior à movimentação de caixas e, enquanto economiza na atividade de embalagem (ausência de embalagens), amplia o custo de armazenagem, pois requer pessoal especializado e equipamentos especiais para o manuseio.

No que tange ao dilema entre o retorno e o não retorno das embalagens, urge mencionar que as embalagens retornáveis promovem a redução dos custos de embalagem, pois inibem novas aquisições, mas ampliam os custos de armazenagem, pois demandam espaços para sua guarda e equipamentos e sistemas para seu manuseio e controle (Stop Waste Partenership, \& Reusable Pallet \& Container Coalition, 2008). Ofek, Katona e Sarvary (2011) destacam que os retornos em geral, não só de embalagens, aumentam substancialmente os custos de armazenagem. O retorno de produtos faz com que atividades de limpeza, lavagem e manuseio tenham que ser desenvolvidas nos armazéns, 
acarretando custos. Ademais, nem sempre os produtos retornados podem ser reaproveitados. Por vezes, eles precisam ser vendidos a terceiros por um valor simbólico, normalmente de $10 \%$ a $20 \%$ do preço original, ou em casos extremos precisam ser destruídos (Ofek et al., 2011).

A Tabela 1 resume os principais aumentos e reduções em custos de atividades logísticas que acarretam reduções e aumentos nos custos de demais atividades e/ou aumentos e reduções no nível de serviço ao cliente.

Tabela 1 - Principais trade-offs de custos logísticos

\begin{tabular}{|c|c|c|}
\hline Atividade & Aumento nos custos & Redução nos custos \\
\hline Transporte & $\begin{array}{l}\text { - Transportes tempestivos } \\
\text { - Manutenção dos produtos nos veículos } \\
\text { - Seleção de trajetos longos } \\
\text { - Não consolidação de lotes } \\
\text { - Transportadores formais e modernos }\end{array}$ & $\begin{array}{l}\text { - Transportes morosos } \\
\text { - Não manutenção dos produtos nos veículos } \\
\text { - Seleção de trajetos curtos } \\
\text { - Consolidação de lotes } \\
\text { - Transportadores informais e individuais }\end{array}$ \\
\hline Estoc & - Produção empurrada & - Produção puxada \\
\hline Armazenagem & $\begin{array}{l}\text { - Descentralização dos armazéns } \\
\text { - Processos automatizados nos armazéns } \\
\text { - Sistemas eficientes de controle de } \\
\text { estocagem } \\
\text { - Realocação dos produtos de um armazém a } \\
\text { outro } \\
\text { - Separação de pedidos estrita } \\
\text { - Precisão na previsão de demanda }\end{array}$ & $\begin{array}{l}\text { - Centralização dos armazéns } \\
\text { - Processos manuais nos armazéns } \\
\text { - Sistemas precários de controle de estocagem } \\
\text { - Ausência de realocação dos produtos de um armazém } \\
\text { a outro } \\
\text { - Separação de pedidos por lotes } \\
\text { - Imprecisão na previsão de demanda }\end{array}$ \\
\hline Embalagem & $\begin{array}{l}\text { - Uso de embalagens padronizadas } \\
\text { - Uso de embalagens a prova d'água } \\
\text { - Uso de embalagens não retornáveis }\end{array}$ & $\begin{array}{l}\text { - Uso de embalagens não padronizadas } \\
\text { - Uso de embalagens não a prova d'água } \\
\text { - Uso de embalagens retornáveis }\end{array}$ \\
\hline
\end{tabular}

Fonte: Elaboração própria.

Nota-se, assim, que há variadas compensações entre os custos logísticos. Por havê-las, sua avaliação torna-se importante para orientar as deliberações logísticas, ponto que será objeto de discussão na próxima seção.

\subsection{Avaliação dos trade-offs de custos logísticos}

Para avaliar os trade-offs, Lambert e Armitage (1979) argumentam que há a necessidade de informações dos componentes de custos e de como mudanças em cada um afetam o custo total. Há necessidade também de informações dos fatores que impactam os custos e as inter-relações de custo. Apenas a conversão a um único denominador comum é capaz de proporcionar comparações apropriadas. Um conjunto de atributos heterogêneos (físicos e operacionais) de uma atividade deve ser convertido a um denominador comum (R\$) (LeKashman \& Stolle, 1965).

O desenho de uma solução que envolve trade-offs envolve mensurações das diferenças de custo, receita e investimento entre as alternativas da atividade analisada e das diferenças de custo, receita e investimento das atividades impactadas (Miller, 1993). Além das diferenças diretas, efeitos indiretos devem ser mensurados. Os diferentes custos e/ou receitas culminam em distintas bases tributárias e determinam impostos díspares sobre o lucro (Amaral \& Guerreiro, 2014).

Após as mensurações terem sido realizadas, deve-se avaliar e comparar as diversas alternativas de ação. Essa avaliação deve induzir à solução que otimize o desempenho econômicofinanceiro global. Se a situação ainda não existe, as soluções que poderão ser implantadas devem ser comparadas. Se modificações são estudadas para uma situação já existente, deve-se promover a comparação da situação atual à solução em avaliação. A complexidade que permeia a formulação das soluções logísticas pede ferramentas que favoreçam o processamento dos dados (Lekashman \& Stolle, 1965). Nesse sentido, constrói-se a hipótese: 
H1: a utilização de simuladores de custo explica positivamente a avaliação dos trade-offs de custos logísticos.

Macintyre (1983) defende, desde a década de 1980, que os contadores devem apoiar robustamente à logística, prestando suporte, auxiliando no controle de custos e disponibilizando informações para a formulação de soluções. Apesar desse potencial, as informações contábeis e gerenciais necessárias à gestão logística ainda são insuficientes ou inadequadas. Pohlen e Lalonde (1994), por exemplo, afirmam que os contadores não conseguiram desenvolver dados que possibilitem uma melhor análise dos custos logísticos. Lambert e Armitage (1979) foram mais enfáticos e sustentaram que os profissionais contábeis demonstram pouco interesse à área, devido, principalmente, à educação recebida nos seus cursos. Pettersson e Segerstedt (2011) concluíram que apenas uma das 30 empresas que entrevistaram mensurava todos os custos logísticos. Além disso, o controle gerencial pode influenciar no desempenho da inovação (Lopes, Beuren, \& Gomes, 2019), o que inclui a inovação e a melhoria dos processos logísticos.

Os contadores gerenciais de uma organização influenciam fortemente, se não completamente, a forma que os custos logísticos são estruturados. Espera-se que o contador gerencial da atualidade tenha um papel mais pró-ativo na disponibilização de informação de custos e de desempenho (Hälinen, 2015). Kučera (2018) destaca, por exemplo, que o controle dos custos logísticos com a comparação entre o planejado e o realizado é cada vez mais imperativo nas organizações e só pode ser realizado, obviamente, com a disponibilidade de informações de custos. A inexistência de informações precisas de custos disponibilizadas pela Controladoria impede uma real e completa implantação do conceito do custo total (Waller \& Fawcett, 2012). Škerlič (2020) destaca ainda que uma informação insuficiente sobre os custos logísticos é o maior obstáculo para a qualidade da decisão logística. Destarte, propõe-se:

H2: o apoio contábil na formulação das soluções logísticas explica positivamente a avaliação dos trade-offs de custos logísticos.

\section{METODOLOGIA}

\subsection{População e amostra}

As características das empresas que apresentam mais tendência de lidar com trade-offs de custos entre variadas atividades logísticas foram levantadas para definição da população da pesquisa. Dois requisitos específicos foram constatados: (i) atuação na atividade industrial e/ou comercial; e (ii) grande porte.

O setor de serviços foi excluído da amostra por possuir ramos em que as empresas não lidam com a transferência de bens físicos e enfrentam uma quantidade limitada de trade-offs. Pequenas empresas também foram excluídas porque, de acordo com Napolitano (1997), elas normalmente atuam com poucas instalações e análises logísticas robustas não lhes são economicamente interessantes.

Optou-se por trabalhar com o banco de dados da Revista Exame, para que a população fosse formada por empresas, localizadas no Brasil, que atendessem aos dois critérios. Essa revista, que é uma das principais publicações brasileiras de negócios, publica anualmente a edição Melhores e Maiores de 2011 (ano base 2010), na qual relaciona as 1.000 maiores empresas não financeiras fixadas no território brasileiro.

A partir desse banco de dados, foram identificadas 659 empresas a compor a população da pesquisa. Para localizar o contato dos profissionais logísticos dessas empresas, o banco de dados da revista Exame foi articulado a um banco de dados de ex-alunos do MBA de Supply Chain Management \& Logística Integrada FIPECAFI e foram realizadas ligações aos telefones centrais das 
empresas. Com essas ações, foi possível identificar o contato (telefônico e eletrônico) de profissionais logísticos de 243 empresas.

O questionário e a carta de apresentação foram enviados ao endereço eletrônico dos 243 profissionais logísticos identificados. 73 respondentes completaram o questionário e passaram a constituir a amostra, conferindo à pesquisa uma taxa de retorno de $30 \%$.

Para a análise do poder estatístico, foi utilizado o software $G^{*}$ Power 3.1.9.2 (Buchner, Erdfelder, Faul, \& Lang, 2014). Foram adotados os valores recomendados por Hair Jr., Anderson, Tatham e Black (2009), isto é, nível de significância de 5\% e poder estatístico de $80 \%$. Como há dois preditores, o $G^{*}$ Power 3.1.9.2 estimou que ao menos 68 participantes devessem fazer parte da amostra. A amostra de 73 respondentes supera, portanto, o patamar mínimo necessário.

$\mathrm{O}$ viés da não resposta foi avaliado mediante duas abordagens. Na primeira, que se refere à proposta de Armstrong e Overton (1977), os respondentes tardios foram equiparados aos não respondentes. As respostas dos 36 participantes que demandaram reiterações foram comparadas às respostas dos 37 participantes que logo participaram da pesquisa e foi verificado que não havia diferença estatística significativa entre elas.

$\mathrm{Na}$ segunda abordagem, o faturamento e o total de ativo dos não respondentes (informação coletada no banco de dados da revista Exame) foi comparado ao faturamento e ao total de ativo dos respondentes. Novamente, não foi detectada diferença estatística significativa entre os grupos. Assim, ambas as abordagens sugeriram que o viés da não resposta não era um problema existente nesta pesquisa.

\subsection{Mensuração das variáveis}

A variável dependente desta pesquisa refere-se à avaliação dos trade-offs de custos logísticos. Ela foi mensurada por meio de seis questões (Tabela 2) que ofereciam uma escala Likert de cinco pontos, cujos extremos iam da afirmação que os estudos, as simulações e as avaliações dos trade-offs "não eram realizados" até a afirmação que tais estudos, simulações e avaliações "eram amplamente realizados". Essas questões foram originalmente elaboradas neste trabalho, com a articulação da literatura à visão prática ofertada no pré-teste.

Tabela 2 - Composição da variável dependente

\begin{tabular}{|c|l|c|c|}
\hline Variável dependente & Escala & Fonte de inspiração \\
\hline Avaliaço dos trade-offs de custos logísticos (AVA) & $\begin{array}{l}\text { A rede logística da empresa e/ou os macro processos logísticos (abastecimento, } \\
\text { logística de fábrica, distribuição) foram objetos de estudos para potencializar os } \\
\text { níveis de serviço ofertados aos clientes ao menor custo total possível. }\end{array}$ & Likert & $\begin{array}{c}\text { Gopal \& Cypress } \\
(1993)\end{array}$ \\
\hline A2 & $\begin{array}{l}\text { São realizadas, de modo sistemático e rotineiro, avaliações do custo total dos } \\
\text { processos logísticos e da rede logística em relação ao nível de serviço oferecido } \\
\text { aos clientes. }\end{array}$ & $\begin{array}{l}\text { Na formulação das soluções logísticas (de diversas amplitudes) são realizadas } \\
\text { análises do custo total logístico versus o nível de serviço ao cliente, ou seja, são } \\
\text { simulados os custos totais em relação aos níveis de serviço possíveis de serem } \\
\text { oferecidos. }\end{array}$ & $\begin{array}{l}\text { Likert } \\
\text { (1965); Chow } \\
\text { (2008) }\end{array}$ \\
\hline A4 & $\begin{array}{l}\text { Na formulação das soluções logísticas (de diversas amplitudes) são realizadas } \\
\text { simulações e análises dos impactos econômico-financeiros resultantes dos } \\
\text { diferentes níveis de serviço. }\end{array}$ & $\begin{array}{l}\text { Lambert \& Armitage } \\
(1979) ; \text { Christopher } \\
(1987)\end{array}$ \\
\hline A5 & $\begin{array}{l}\text { Na formulação das soluções logísticas (de diversas amplitudes) são } \\
\text { identificadas e analisadas as trocas compensatórias de custos mais relevantes. }\end{array}$ \\
\hline A6 & $\begin{array}{l}\text { Na formulação das soluções logísticas (de diversas amplitudes) são realizadas } \\
\text { simulações e análises dos impactos econômico-financeiros das trocas } \\
\text { compensatórias de custos mais relevantes. }\end{array}$ & $\begin{array}{c}\text { LeKashman \& Stolle } \\
\text { (1965) }\end{array}$ \\
\hline
\end{tabular}

Fonte: Elaboração própria. 
Vale mencionar que a escala de cinco pontos foi escolhida porque, de acordo com Weijters, Cabooter e Schillewaert (2010), essa é a melhor escala quando se tem o objetivo de estimar a relação linear entre variáveis e quando se lida com uma população que não é de estudantes. Além disso, a escala de cinco pontos oferece a possibilidade de selecionar uma posição intermediária, importante para que participantes com posturas neutras não se sintam obrigados a escolher uma posição polar que não representa sua verdadeira percepção.

Para que a variável pudesse ser expressa por um único número, as respostas oferecidas às seis questões foram articuladas por meio da Equação 1. Nessa equação, $i=$ observação (empresa); $\mathrm{q}_{i}=$ escore da resposta de cada questão em cada observação (de 1 a 5); $n=$ número de questões (seis); e $\mathrm{VD}_{i}=$ variável dependente apurada a cada observação.

$$
V D_{i}=\frac{\sum_{i=1}^{6} q_{i}}{n}
$$

Equação 1

As variáveis independentes são duas (Tabela 3). Uma referente à disponibilidade de simuladores de custo total e outra ao apoio contábil. A primeira foi mensurada por uma questão dicotômica (sim ou não), enquanto a segunda foi mensurada por meio de questão que, mais uma vez, oferecia a escala Likert de cinco pontos. Nessa escala, os extremos iam da "não ajuda" a "ajuda total" proporcionada pelas informações contábeis. As questões foram originalmente elaboradas neste trabalho.

Tabela 3 - Composição das variáveis independentes

\begin{tabular}{|c|c|c|c|}
\hline \multicolumn{2}{|c|}{ Variáveis independentes } & Escala & Fonte de inspiração \\
\hline \multicolumn{4}{|c|}{ 1. Utilização de Simuladores de Custo Total } \\
\hline SIM & $\begin{array}{l}\text { No desenho das soluções logísticas são usados simuladores de } \\
\text { custo total para rede logística e/ou simuladores de custo total para } \\
\text { projetos logísticos. }\end{array}$ & Dicotômica & Fellous (2009) \\
\hline \multicolumn{4}{|c|}{ 2. Apoio Contábil na Apuração dos Trade-off de Custos Logísticos } \\
\hline CAT & $\begin{array}{l}\text { As informações recebidas da Controladoria ajudam a apurar as } \\
\text { trocas compensatórias de custos necessárias à mensuração do custo } \\
\text { total logístico. }\end{array}$ & Likert & $\begin{array}{l}\text { Tyndall \& Busher (1985); } \\
\text { Lambert \& Armitage (1979) }\end{array}$ \\
\hline
\end{tabular}

Fonte: Elaboração própria.

Para identificar a relação entre a variável dependente e as variáveis independentes, conduziuse uma análise de regressão linear múltipla com o uso do software Statistical Package for Social Sciences Programme - SPSS (versão 19). Ademais, com o uso do software, apuraram-se as estatísticas descritivas de cada variável e as correlações entre elas.

\subsection{Coleta de dados}

A inexistência de disponibilidade de dados sobre as variáveis da pesquisa tornou necessária a coleta de dados primários junto às empresas brasileiras. Essa coleta ocorreu mediante um levantamento (survey). Para realizar o levantamento, esta pesquisa fez uso do questionário, que compreende um conjunto ordenado e consistente de perguntas a respeito de variáveis e de situações que se deseja medir ou descrever (Martins \& Theóphilo, 2009). O questionário foi dividido em quatro blocos e contemplou ao todo 26 questões, sendo 10 de caracterização e 16 específicas sobre os tradeoffs.

Cabe destacar que para assegurar a validade do questionário elaborado, foi realizado um préteste antes da sua aplicação, tal como sugerido por Malhotra e Grover (1998). O pré-teste foi dividido em três etapas. A primeira fase consistiu na apresentação inicial do questionário a professores experientes e a um pesquisador, com o objetivo de avaliação preliminar do conteúdo apresentado.

Após proceder às mudanças sugeridas na fase anterior, partiu-se para a segunda etapa do préteste. Nessa segunda fase, o questionário foi aplicado a três pessoas relacionadas à logística (um 
profissional logístico, um consultor logístico e um docente logístico) para verificar se os termos utilizados nas perguntas são de compreensão dos respondentes, se as perguntas são entendidas como deveriam ser, se as opções de respostas às perguntas fechadas estão completas, se a sequência das perguntas está correta, se não há objeções na obtenção das respostas, e se a forma de apresentar a pergunta não está causando viés (Mattar, 1997). Nessa fase, percebeu-se a necessidade de adequações, sobretudo às possibilidades de respostas à questão do curso de formação.

No decorrer da construção da pesquisa, viu-se a necessidade de incluir, excluir e/ou modificar questões. Para assegurar a permanência da validade do instrumento de coleta, foi novamente verificado com o consultor logístico, se as qualidades do questionário (compreensibilidade, clareza, completude, facilidade de preenchimento e tempo de resposta aceitável) foram mantidas. Nessa etapa, constatou-se que não seria preciso realizar novos ajustes.

Para a validação conclusiva, realizou-se a terceira e última fase do pré-teste, em que um gestor logístico, com perfil semelhante aos potenciais respondentes, respondeu ao questionário. Não foram detectados problemas na compreensibilidade das questões, na facilidade ou na dificuldade do preenchimento e no tempo consumido para completar o questionário.

Cuidados também foram tomados com relação à confiabilidade do questionário. $\mathrm{O}$ alfa de Cronbach foi calculado para essa finalidade após as respostas terem sido coletadas. O alfa apurado, contemplando as questões usadas para mensurar os constructos desta pesquisa, foi de 0,6 , que corresponde a um nível aceitável, segundo Bryman (2012).

Para obter respostas, primeiramente encaminhou-se a carta de apresentação e o questionário em uma mensagem eletrônica direcionada para todos os profissionais identificados na composição da população da pesquisa. Depois, telefonou-se para cada uma das empresas, com o fim de constatar se os profissionais contatados eletronicamente realmente atuavam no contexto logístico. O questionário foi disponibilizado de duas formas, em word e na plataforma do Google forms, e ficou aberto para receber respostas por 48 dias, entre os dias 02 de fevereiro e 20 de março de 2012.

\section{ANÁLISE E DISCUSSÃO DOS RESULTADOS}

\subsection{Perfil da amostra}

A amostra da pesquisa é formada principalmente por empresas que atuam no ramo industrial (90\%), 66 empresas são desse ramo, enquanto apenas 7 são de comércio. Essa composição está alinhada com a população da pesquisa, composta em maior extensão por empresas industriais (73\% contra $27 \%$ de empresas comerciais). Com referência ao controle, sublinha-se que praticamente metade da amostra (42,47\%) possui controle (acionário ou grupo de controle) brasileiro, conforme evidencia a Tabela 4.

Tabela 4 - Controle acionário

\begin{tabular}{ccc}
\hline Controle & Quantidade de empresas & $\%$ \\
\hline Brasileiro & 31 & $42,47 \%$ \\
Americano & 12 & $16,44 \%$ \\
Francês & 8 & $10,96 \%$ \\
Alemão & 5 & $6,85 \%$ \\
Suíço & 5 & $6,85 \%$ \\
Outros & 12 & $16,44 \%$ \\
\hline Total & 73 & $100,00 \%$ \\
\hline
\end{tabular}

Fonte: Dados da pesquisa.

Vale também mencionar que, por ser oriunda do banco de dados da Revista Exame Melhores e Maiores, a amostra é formada por grandes empresas, havendo uma concentração (34\%) na faixa de faturamento entre 1 e 2 bilhões de reais, detalhado na Tabela 5. 
Tabela 5 - Faturamento

\begin{tabular}{ccc}
\hline Faturamento (em R\$ milhões) & Quantidade de empresas & $\%$ \\
\hline Até R \$ 500 & 6 & $8,22 \%$ \\
De R 500 a R\$ 1.000 & 13 & $17,81 \%$ \\
De R 1.000 a R 2.000 & 25 & $34,25 \%$ \\
De R 2.000 a R \$ 5.000 & 16 & $21,92 \%$ \\
Acima de R\$ 5.000 & 13 & $17,81 \%$ \\
\hline Total & 73 & $100,00 \%$ \\
\hline
\end{tabular}

Fonte: Dados da pesquisa.

Em relação aos respondentes, cabe destacar que a maioria $(68 \%)$ atua específica e exclusivamente na área almejada da pesquisa (logística), conforme mostra a Tabela 6.

Tabela 6 - Área de atuação

\begin{tabular}{ccc}
\hline Área de atuação na empresa & Quantidade de empresas & $\%$ \\
\hline Compras/Suprimentos & 9 & $12,33 \%$ \\
Distribuição & 4 & $5,48 \%$ \\
Exportação/Importação/Comércio Exterior & 4 & $5,48 \%$ \\
Logística & 44 & $60,27 \%$ \\
Operações/Produção & 4 & $5,48 \%$ \\
Projetos logísticos & 6 & $8,22 \%$ \\
Serviços de suporte ao cliente & 2 & $2,74 \%$ \\
\hline Total & 73 & $100,00 \%$ \\
\hline
\end{tabular}

Fonte: Dados da pesquisa.

Finalmente, no que se refere à função, cabe destacar que a maior parte dos respondentes (89\%) é analista (20\%) ou possui função gerencial (69\%). A Tabela 7 evidencia os detalhes.

Tabela 7 - Função

\begin{tabular}{ccc}
\hline Cargo de atuação na empresa & Quantidade de empresas & $\%$ \\
\hline Analista & 15 & $20,55 \%$ \\
Chefe & 2 & $2,74 \%$ \\
Supervisor & 6 & $8,22 \%$ \\
Coordenador & 13 & $17,81 \%$ \\
Gerente & 26 & $35,62 \%$ \\
Diretor & 3 & $4,11 \%$ \\
Outros & 8 & $10,96 \%$ \\
\hline Total & 73 & $100,00 \%$ \\
\hline
\end{tabular}

Fonte: Dados da pesquisa.

Nota-se, assim, que a amostra da pesquisa é formada majoritariamente por profissionais técnicos (analistas) de áreas logísticas e correlatas das maiores empresas do Brasil, cujo controle acionário é principalmente brasileiro.

\subsection{Estatística descritiva}

$\mathrm{Na}$ Tabela 8 são apresentadas as estatísticas descritivas de todas as variáveis dependentes e independentes da pesquisa. São demonstrados os valores mínimos e máximos de cada variável, também são revelados suas medianas e desvios padrões (SD).

Primeiramente, pode-se perceber que a mediana da avaliação dos trade-offs de custos logísticos $(3,67)$ é maior do que o ponto intermediário da escala Likert adotada (3.00). Esse achado indica que, no geral, a maior parte das empresas da amostra avalia, ainda que moderadamente, os trade-offs. Constatou-se ênfase na avaliação de trade-offs na formulação de soluções de maiores amplitudes, relacionadas à rede logística e aos processos logísticos. $\mathrm{O}$ maior custo envolvido e a 
maior disponibilidade de softwares comerciais das amplas soluções podem impulsionar essa priorização. Cabe reforçar que a avaliação dos trade-offs de custos logísticos é essencial para que o conceito da logística integrada seja efetivamente implementado (Lambert \& Armitage, 1979) e, por isso, pode ser priorizada em maiores soluções.

Tabela 8 - Estatística Descritiva

\begin{tabular}{lccccc}
\hline \multicolumn{1}{c}{ Variável } & n & Mínimo & Máximo & Mediana & Desvio Padrão \\
\hline ASS - Avaliação dos trade-offs de custos logísticos & 73 & 1 & 5 & 3,67 & 0.85 \\
SIM - Utilização de simuladores de custo total & 73 & 0 & 1 & 1,00 & 0.50 \\
CTA - Apoio contábil na apuração dos trade-offs & 42 & 1 & 5 & 3,50 & 1.04 \\
\hline
\end{tabular}

Fonte: Dados da pesquisa.

No que diz respeito aos simuladores, ainda que mediana tenha sido 1,00 , constatou-se que $42 \%$ das empresas ainda não usam quaisquer simuladores, o que gera preocupação, pois segundo LeKashman e Stolle (1965), a análise funcional do custo total envolve mensurações e análises de inúmeras combinações, que exigem modelos computacionais favorecedores do processamento dos dados.

No que se refere ao apoio contábil, cabe destacar que este estudo observou de que o apoio é limitado (mediana 3,50), indicando que informações de custos necessárias às análises de trade-offs podem não estar disponíveis. Os profissionais logísticos mencionaram que ainda não recebem sistematicamente informações contábeis apropriadas: menos de um terço dos respondentes afirma que a Controladoria remete dados contábeis adequados, de modo similar à constatação de Lambert e Quinn (1981). Assim como Lambert e Armitage (1979) sinalizaram há três décadas, replica-se neste estudo o achado de uma lacuna entre o nível de informação contábil que apoiaria a logística na avaliação dos trade-offs e na apuração do custo total e o nível que efetivamente é encontrado nas empresas.

\subsection{Associação entre as variáveis}

Na Tabela 9 é evidenciada a matriz com os coeficientes da correlação entre as variáveis. Cabe mencionar que avaliação dos trade-offs foi mensurada com a conjugação dos escores assinalados às questões, conforme detalhes na Equação 1, os simuladores como uma variável dummy (sim ou não) e o apoio contábil diretamente como o escore assinalado à questão correspondente. Pode-se notar que as variáveis independentes são positivamente associadas à variável dependente e que as associações são significativas ao $\mathrm{p}<0.001$.

Tabela 9 - Matriz de correlação

\begin{tabular}{cccc}
\hline & AVA & SIM & CAT \\
\hline AVA & 1 & & \\
SIM & $0,535^{* *}$ & 1 & 1 \\
CAT & $0,534^{* *}$ & 0,09 & 1 \\
\hline
\end{tabular}

** significativa ao nível de $1 \%$

Fonte: Dados da pesquisa.

Na Tabela 10, por sua vez, são revelados os resultados apurados na análise de regressão linear múltipla. Com ela, pode-se observar que o modelo é estatisticamente significativo e que 53,1 por cento da variância $(50,7 \%$, se ajustada) da variável dependente é explicada pelas duas variáveis independentes.

$\mathrm{Na} \mathrm{H} 1$, assumiu-se que a utilização de simuladores de custo explica positivamente a avaliação dos trade-offs de custos logísticos. A análise de regressão linear múltipla confirmou essa expectativa e viabilizou a não rejeição da hipótese. O uso de simuladores tem um coeficiente positivo de 0,654 e 
explica significativamente a avaliação dos trade-offs $(\mathrm{t}=4,515, \mathrm{p}<0.001)$. Esse resultado assemelhase à argumentação de Gustin, Daugherty e Stank (1995), de que o uso de sistemas de informação e de tecnologia computadorizada provê o potencial de identificar rápida e precisamente oportunidades de otimização de custos. Corrobora-se ainda a defesa de Song e Wang (2009), de que instrumentos que disponibilizem informações são um dos primeiros pré-requisitos para a identificação e o gerenciamento dos conflitos entre os custos logísticos.

Tabela 10 - Regressão múltipla

\begin{tabular}{ccccc}
\hline Variável & Coeficiente & Erro Padrão & Estatística - t & Probabilidade \\
\hline Intercepto & 2,268 & 0,257 & 8,825 & 0,000 \\
SIM & 0,654 & 0,145 & 4,515 & 0,000 \\
CTA & 0,300 & 0,067 & 4,449 & 0,000 \\
\hline R = 0,729 & $\mathbf{R}^{\mathbf{2}=\mathbf{0 , 5 3 1}}$ & $\mathbf{R}^{\mathbf{2}}$ Ajustado $=\mathbf{0 , 5 0 7}$ & $\mathbf{F = 2 2 , 0 6 5}$ & $\mathbf{p = 0 , 0 0 0}$ \\
\hline
\end{tabular}

Fonte: Dados da pesquisa.

$\mathrm{Na} \mathrm{H} 2$, conjecturou-se que o apoio contábil na formulação das soluções logísticas explica positivamente a avaliação dos trade-offs de custos logísticos. Os resultados da análise de regressão linear múltipla ratificaram essa conjectura e permitiram não rejeitar a hipótese. O apoio contábil explica significativamente a avaliação dos trade-offs $(\mathrm{t}=4,449, \mathrm{p}<0.001)$, tendo um coeficiente positivo de 0,300. Esse achado assemelha-se aos resultados de Moura e Beuren (2003), de que a Controladoria pode influenciar positivamente o processo decisório dos gestores com o oferecimento de informações.

Especificamente no que se refere às decisões logísticas, cabe mencionar que Lambert e Stock (1992) defenderam que a qualidade da informação contábil influencia diretamente a habilidade dos gestores logísticos nas deliberações. Afinal, como Lambert (1975, p. 54) cita, se os trade-offs são o "coração" da logística, as informações adequadas de custo são o "coração" dos trade-offs.

Destarte, os achados conjugados desta pesquisa reforçam a relevância de dispor de informações apropriadas para avaliar os trade-offs. Dados necessários disponibilizados pela área contábil e tratados pelos simuladores propiciam uma análise pormenorizada dos trade-offs. -Assim, tendem a favorecer a tomada da decisão logística. Logo, os profissionais da área passam a ter conhecimento que podem otimizar suas deliberações se dispuserem do apoio contábil e de ferramentais tecnológicos. Assim, podem sentir-se estimulados a implantarem essas questões em suas empresas.

\section{CONCLUSÃO}

Há estudos que admitem a existência dos trade-offs e discutem a necessidade da sua avaliação. Contudo, esses estudos, que possuem um escopo ampliado de exploração dos custos logísticos, acabam tratando os trade-offs como tema acessório, não como foco da investigação. Dessa forma, o preenchimento de detalhes dos trade-offs pode completar lacunas na literatura e oferecer contribuições à teoria e à prática.

Nesse sentido, este estudo buscou responder a seguinte questão: "Quais fatores explicam a extensão de avaliação dos trade-offs de custos logísticos" e constatou que a utilização de simuladores de custo total e o apoio contábil ajudam a entender o nível de avaliação dos trade-offs.

A principal contribuição que este artigo oferece à teoria fundamenta-se na constituição de uma forma estruturada para mensurar a avaliação dos trade-offs. Essa estruturação fomenta a redução de inconsistências, melhora a comparabilidade entre estudos e favorece o estabelecimento de críticas para o tema. Vale destacar que essa apresentação acrescenta à literatura do tema, ao passo que a mesma ainda é incipiente e parcial. O periódico Journal of Business Logistics inclusive lançou chamadas por estudos que explorem, sob vários prismas, o conceito do custo total (Waller \& Fawcett, 
2012). Outro ponto que cabe destacar é que esta pesquisa buscou abordar os trade-offs de forma consolidada, buscando transpor a barreira citada por Mentzer et al. (2004), de que os pesquisadores logísticos têm desenvolvido estudos restritos a componentes individuais logísticos e feito pouco esforço para construir uma teoria unificada da logística.

Do ponto de vista prático, destaca-se a interdisciplinaridade que este artigo promove ao integrar a logística à contabilidade. Este estudo contribui com a logística, ao evidenciar que a análise dos trade-offs é necessária para que seja encontrado o equilíbrio entre os recursos consumidos e os serviços oferecidos. Esta pesquisa também contribui com a contabilidade, ao demonstrar que a avaliação dos trade-offs é elementar para que seja otimizado o custo total e, assim, seja melhorado o resultado econômico global da organização.

Ademais, há a implicação de demonstrar que o uso de simuladores e o apoio de controladoria podem indicar caminhos para melhorar o resultado econômico-financeiro da logística, já que como Bley (2004) indica, o montante de receitas de vendas consumido pelos custos logísticos é expressivo, compreendendo de 7 a 10\% das vendas líquidas. Essa magnitude de custos somada à intensificação da concorrência realça a necessidade de boa performance das empresas. A logística, ao poder propiciar o oferecimento de um melhor serviço ao cliente a um menor custo (Fellous, 2009), constituiu um dos fatores decisivos para a competitividade e, consequentemente, para o desempenho das firmas (Faleiros, 2006). Silva in Faleiros (2006, p. B12) argumenta que "a logística está valorizada porque os produtos tendem a virar commodity. Quem tiver agilidade na área e conseguir um nível de serviço melhor sendo mais eficiente, pode ter custos menores ou aumentar sua margem de lucro".

A revisão da literatura e os achados específicos deste artigo também mostraram que os tradeoffs de custos logísticos são um tema que ainda carece de mais estudos. Nesse sentido, para expandir a literatura e estimular pesquisas futuras sobre o assunto, elaborou-se a Tabela 11, na qual é desenvolvida uma detalhada agenda de pesquisa com propostas de questões para complementar estes achados.

Tabela 11 - Oportunidades de pesquisas futuras

\begin{tabular}{|c|c|}
\hline Achados & Sugestões para questões de pesquisas futuras \\
\hline $\begin{array}{l}\text { A utilização de simuladores de custo } \\
\text { explica positivamente a avaliação dos } \\
\text { trade-offs de custos logísticos. }\end{array}$ & $\begin{array}{l}\text { Quais são as características dos simuladores que mais favorecem a avaliação } \\
\text { dos trade-offs? } \\
\text { Qual é a relação entre a presença de simuladores e as características das } \\
\text { empresas (por exemplo, tamanho, faturamento etc.)? } \\
\text { Qual é a relação entre a área da empresa que propõe a implantação de um } \\
\text { simulador e a aceitação da ideia? } \\
\text { Quais áreas mais contribuem com a manutenção do simulador? }\end{array}$ \\
\hline $\begin{array}{l}\text { O apoio contábil na formulação das } \\
\text { soluções logísticas explica } \\
\text { positivamente a avaliação dos trade-offs } \\
\text { de custos logísticos. }\end{array}$ & $\begin{array}{l}\text { Quais são as características da controladoria que mais favorecem a avaliação } \\
\text { dos trade-offs? } \\
\text { Qual é a relação entre a existência de uma controladoria que apoia a logística } \\
\text { e as características das empresas (por exemplo, tamanho, faturamento etc.)? } \\
\text { Qual é a relação entre a formação e/ou experiência do contador e a existência } \\
\text { de uma controladoria que apoia a logística? } \\
\text { Quais tipos de informações a controladoria proporciona? }\end{array}$ \\
\hline
\end{tabular}

Fonte: Elaboração própria.

Finalmente, cabe esclarecer que este estudo possui limitações e que, portanto, generalizações dos resultados obtidos não são indicadas e devem ser vistas com cautela. A parcela da população acessada com a utilização de uma amostra não probabilística restringe a validade externa da pesquisa. A contraposição entre a viabilidade e os procedimentos de amostragem impediu que métodos de amostragem probabilística fossem seguidos. Outra limitação refere-se à consideração dos profissionais logísticos como respondentes do estudo, que emanou do próprio objetivo da pesquisa, mas trouxe como consequência conclusões embasadas nas suas percepções. Nesse sentido, recomenda-se também que pesquisas similares busquem acessar outras populações e outros profissionais ajudem a formar uma base de estudos comparativos. 
O instrumento de coleta de dados também traz limitações, devido ao fato de que as interpretações de cada respondente às questões podem ser distintas, por refletir o discernimento e o julgamento que cada profissional possui. Novos estudos podem acessar alternativamente os constructos, com o uso de técnicas qualitativas, por exemplo. Há, finalmente, a limitação advinda da própria escolha do tema, que demandou a elaboração inicial de constructos. Novas pesquisas ainda são necessárias para confirmar a definição trazida, ou para identificar outros possíveis constructos e variáveis.

\section{REFERÊNCIAS}

Amaral, J. V., \& Guerreiro, R. (2014). Knowledge and assessment of logistics cost trade-offs: a study with Brazilian professionals. Revista Contabilidade \& Finanças - USP, 25(65), 111-123.

Armstrong, J. S., \& Overton, T. S. (1977) Estimating nonresponse bias in mail surveys. Journal of Marketing Research, 14(3), 396-402.

Arvis, J. F., Ojala, L., Wiederer, C., Shepherd, B., Raj, A., Dairabayeva, K., \& Kiiski, T. (2018). Logistics Performance Index and its indicators. (Working Paper). Washington: The International Bank for Reconstruction and Development/The World Bank.

Arvis, J. F., Raballand, G., \& Marteau, J. F. (2007). The cost of being landlocked: logistics costs and supply chain reliability. (Working Paper 4258). Washington: World Bank Policy Research.

Auler, J. R., Teixeira, A. J. C., Teixeira, A. M. C. Baptista, E. C. S. (2009). Impacto da evolução futura dos preços dos ovos no desempenho de uma granja de aves de postura comercial. Revista Universo Contábil, 5(2), 58-70.

Bhatnagar, R., \& Teo, C. C. (2009). Role of logistics in enhancing competitive advantage: A value chain framework for global supply chains. International Journal of Physical Distribution \& Logistics Management, 39(9), 202-226.

Bley, D. (2004). Improving logistics. Strategic Finance, 86(4), 38-41.

Bowersox, D. J., \& Closs, D. J. (2009). Logística empresarial: o processo de integração da cadeia de suprimento. São Paulo: Atlas.

Bryman, A. (2012). Social Research Methods. 4th ed. New York: Oxford University Press.

Buchner, A., Erdfelder, E., Faul, F., \& Lang, A. G. (2014). Software G*Power 3.1.9.2. Germany: Universität Kiel.

Busher, J. R., \& Tyndall, G. R. (1987). Logistics excellence. Management Accounting, 69(2), 32-39.

Chopra, S., \& Meindl, P. (2003). Gerenciamento da cadeia de suprimento, estratégia, planejamento e operação. São Paulo: Prentice Hall.

Chow, G. (2008). Getting back to basics. Canadian Transportation Logistics, 111(10), 40.

Christopher, M. (1987). Assessing the costs of logistics service. Working paper, Cranfield School of Management, Working Paper SWP 61/87.

Coyle, J. J., Langley Jr., C. J., Gibson, B. J., Novack, R. A., \& Bardi, E. J. (2008). Supply chain management: a logistic perspective. 8th ed. Mason: South-Western Cengage Learning.

Donselaar, K., Woensel, T., Broekmeulen, R., \& Fransoo, J. (2006). Inventory control of perishables in supermarkets. International Journal of Production Economics, 104(2), 462-472.

Faria, A. C. \& Costa, M. F. G. (2007). Gestão de custos logísticos. 1 ed. São Paulo: Atlas.

Faleiros, M. (02 de março de 2006). Logística abre novo campo para executivos. $O$ Estado de $S$. Paulo, 41043, B12.

Fellous, S. M. (2009). Gestão da cadeia de suprimentos no Brasil e a utilização de instrumentos da contabilidade gerencial: uma avaliação sob a perspectiva dos profissionais envolvidos. Dissertação (Mestrado em Ciências Contábeis) Faculdade de Economia, Administração e Contabilidade da Universidade de São Paulo.

Gopal, C., \& Cypress, H. (1993). Integrated distribution management: competing on customer service, time, and cost. Homewood: Irwin. 
Gu, J., Goetschalckx, M., \& Mcginnis, L. F. (2010). Research on warehouse design and performance evaluation: a comprehensive review. European Journal of Operational Research, 203(3), 539549.

Gustin, C. A., Daugherty, P. J., \& Stank, T. P. (1995). The effects of information availability on logistics integration. Journal of Business Logistics, 16(1), 01-21.

Hair Jr., J. F., Anderson, R. E., Tatham, R. L., \& Black, W. C. (2009). Análise multivariada de dados. 6 a ed. Porto Alegre: Bookman.

Hälinen, H. M. (2015). Understanding the concept of logistics cost in manufacturing. 2015. $112 \mathrm{f}$. $\mathrm{Ph}$. D. Thesis - Turku School of Economics, University of Turku, Turku.

Hozak, K., \& Collier, D. A. (2008). RFID as an enabler of improved manufacturing performance. Decision Sciences, 39(4), 859-881.

ILOS - Especialistas em Logística e Supply Chain. (2017). Brochura do panorama ILOS - custos logísticos no Brasil - 2017. Rio de Janeiro: ILOS.

Ishfaq, R., \& Raja, U. (2020) Effectiveness of frequent inventory audits in retail stores: an empirical evaluation. The International Journal of Logistics Management, 31(1), 21-41.

Jain, C. L. (2004). How to measure the cost of a forecast error. The Journal of Business Forecasting Methods \& Systems, 22(4), 02, 29-30.

Jain, C. L. (2007). Benchmarking forecasting models. The Journal of Business Forecasting, 25(4), 14-17.

Jammernegg, W., \& Reiner, G. (2007). Performance improvement of supply chain processes by coordinated inventory and capacity management. International Journal of Production Economics, 108(1-2), 183-190.

Kämäräinen, V., \& Punakivi, M. (2002). Developing cost-effective operations for the e-grocery supply chain. International Journal of Logistics Research and Applications, 5(3), 285-298.

Kučera, T. (2018). Calculation of logistics costs in context of logistics controlling. Transport Means - Proceedings of the International Conference, Trakai, Lithuania, 22.

Lambert, D. M. (1975). The development of an inventory costing methodology: a study of the costs associated with holding inventory. 1975. 205 f. Ph. D. Dissertation (Philosophy), Department of Marketing, The Ohio State University, Columbus.

Lambert, D. M., \& Armitage, H. M. (1979). Distribution costs: the challenge: the key to managing the physical distribution function is total cost analysis, rather than haphazard stabs at cutting specific costs. Management Accounting (pre-1986), 60(11), 33-37, 45.

Lambert, D. M., \& Lalonde, B. J. (1976). Inventory carrying costs. Management Accounting (pre1986), 58(2), 31-35.

Lambert, D. M., \& Lewis, C. M. (1983). Managing customer service to build market share and increase profit. Business Quarterly, 48(3), 50-57.

Lambert, D. M., \& Quinn, R. (1981). Increase profitability by managing the distribution function. Ivey Business Journal, 46(1), 56-64.

Lambert, D. M, \& Stock, J. R. (1992). Strategic logistics management. 3rd ed. Boston: Irwin/Mcgraw-Hill.

Lee, H.L., \& Billington, C. (1992). Managing supply chain inventory: pitfalls and opportunities. Sloan Management Review, 33(3), 64-73.

Lekashman, R., \& Stolle, J. F. (1965). The total cost approach to distribution. Business Horizons, $8(1), 33-46$.

Lewis, H. T., \& Culliton, J. W. (1956). Characteristics of air freight and its market. In H. T. Lewis, J. W. Culliton, \& J. D. Steele (Orgs.), The role of air freight in physical distribution. Boston: Division of Research, Graduate School of Business Administration, Harvard University.

Lin, B., Collins, J., \& Su, R. K. (2001). Supply chain costing: an activity-based perspective. International Journal of Physical Distribution \& Materials Management, 31(10), 702-713. 
Little, W. I. (1977). The cellular flow logistics costing system. International Journal of Physical Distribution, 7(6), 306-329.

Lopes, I. F., Beuren, I. M., \& Gomes, T. (2019). Influência do uso do sistema de controle gerencial e da estratégia organizacional no desempenho da inovação. Revista Universo Contábil, 15(1), 85105.

Macintyre, D. K. (1983). Marketing costs: a new look. Management Accounting (pre-1986), 64(9), 20-28.

Malhotra, M. K., \& Grover, V. (1998). An assessment of survey research in POM: from constructs to theory. Journal of Operations Management, 16(4), 407-425.

Martins, G., \& Theóphilo, C. R. (2009). Metodologia da investigação científica para ciências sociais aplicadas. 2 ed. São Paulo: Atlas.

Mattar, F. N. (1997). Pesquisa de marketing: metodologia, planejamento. 4. ed. São Paulo: Atlas.

Mckinnon, A. (2007). Decoupling of road freight transport and economic growth trends in the UK: an exploratory analysis. Transport Reviews: A Transnational Transdisciplinary Journal, 27(1), 37-64.

Mentzer, J. T., Min, S., \& Bobbitt, L. M. (2004). Toward a unified theory of logistics. International Journal of Physical Distribution \& Logistics Management, 34(8), 606-627.

Miller, T. C. (1993). By air or by sea? The Journal of European Business, 4(5), 50-52.

Miller, T. C., \& Smith, S. (2011). Integrate network design with warehouse design. Material Handling \& Logistics, 01 Feb. 2011, 05. Recuperado de https://www.mhlnews.com/archive/integrate-network-design-warehouse-design. Acesso em: 16 jan. 2021.

Moghaddam, S. T., Javadi, M., \& Molana, S. M. H. (2019). A reverse logistics chain mathematical model for a sustainable production system of perishable goods based on demand optimization. Journal of Industrial Engineering International, 15(4), 709-721.

Moons, K., Waeyenbergh, G., \& Pintelon, L. (2019). Measuring the logistics performance of internal hospital supply chains - a literature study. Omega, 82(C), 205-2017.

Moura, V. M., \& Beuren, I. M. (2003). O suporte informacional da Controladoria para o processo decisório da distribuição física de produtos. Revista Contabilidade \& Finanças, 14(31), 45-65.

Napolitano, M. (1997). Distribution network modeling. Industrial Engineer, 29(6), 20-24.

Napolitano, M. (2011). 6 tips for optimizing the distribution network. Logistics Management, 50(7), 54-56, 58.

Ofek, E., Katona, Z., \& Sarvary, M. (2011). Bricks and clicks": the impact of product returns on the strategies of multichannel retailers. Marketing Science, 30(1), 42-60.

Parker, D. D. (1962). Improved efficiency and reduced cost in marketing. Journal of Marketing, 26(2), 15-21.

Pettersson, A., \& Segerstedt, A. (2011). Performance measurements in supply chain within Swedish industry. International Journal of Logistics Systems and management, 9(1), 69-88.

Pohlen, T. L., \& Lalonde, B. J. (1994). Implementing activity based costing (ABC) in logistics. Journal of Business Logistics, 15(2), 01-23.

Rantasila, K., \& Ojala, L. (2015). National-level logistics costs: an overview of extant research. International Journal of Logistics Research and Applications, 18(4), 313-324.

Russell, M. L., \& Meller, R. D. (2003). Cost and throughput modeling of manual and automated order fulfillment systems. IIE Transactions, 35(7), 589-603.

Škerlič, S. (2020) Factors that influence logistics decision making in the supply chain of the automotive industry. Transport Problems, 15(3), 117-126.

Solakivi, T., Hofmann, E., Töyli, J. \& Ojala, L. (2018) The performance of logistics service providers and the logistics costs of shippers: a comparative study of Finland and Switzerland. International Journal of Logistics Research and Applications, 21(4), 444-463. 
Song, H., \& Wang, L. (2009). The status and development of logistics cost management: evidence from Mainland China. Benchmarking: An International Journal, 16(5), 657-670.

Souza, M. A., Weber, E. L., \& Campos, R. H. (2015). Práticas de gestão de custos logísticos internos: estudo de caso em empresa moveleira do sul do Brasil. Revista Contemporânea de Contabilidade, 12(25), 27-46.

Stank, T., Esper, T., Goldsby, T. J., Zinn, W., \& Autry, C. (2019). Toward a Digitally Dominant Paradigm for twenty-first century supply chain scholarship. International Journal of Physical Distribution \& Logistics Management, 49(10), 956-971.

Stop Waste Partnership, Reusable Pallet \& Container Coalition (RPCC). (2008). A cost comparison model for Reusable Transport Packaging. Recuperado de https://reusables.org/wpcontent/uploads/2016/06/Reusables-102.pdf. Acesso em: 16 jan. 2021.

Talley, W. K., \& Ng, M. (2017). Hinterland transport chains: Determinant effects on chain choice. International Journal of Production Economics, 185, 175-179.

Tyndall, G. R., \& Busher, J. R. (1985). Improving the management of distribution with cost and financial information. Journal of Business Logistics, 6(2), 01-18.

Vanelslander, T., Deketele, L., \& Van Hove, D. (2013). Commonly used e-commerce supply chains for fast moving consumer goods: comparison and suggestions for improvement. International Journal of Logistics Research and Applications, 16(3), 243-256.

Vernuccio, M., Cozzolino, A., \& Michelini, L. (2010). An exploratory study of marketing, logistics, and ethics in packaging innovation. European Journal of Innovation Management, 13(3), 333354.

Waller, M. A., \& Fawcett, S. E. (2012). The total cost concept of logistics: one of many fundamental logistics concepts begging for answers. Journal of Business Logistics, 33(1), 1-3, 2012.

Weijters, B., Cabooter, E., \& Schillewaert, N. (2010). The effect of rating scale format on response styles: the number of response categories and response category labels. International Journal of Research in Marketing, 2(3), 236-247.

Wu, S. J., \& Closs, D. J. (2009). The impact of integrating return components planning with purchasing decisions on purchasing performance: a contingency perspective. The International Journal of Logistics Management, 20(1), 57-78. 